\title{
Variation of grain nutritional quality among Thai purple rice genotypes grown at two different altitudes
}

\author{
Benjavan Rerkasem ${ }^{\mathrm{a}}$, Suchada Jumrus ${ }^{\mathrm{b}}$, Narit Yimyam $^{\mathrm{c}}$, Chanakan Prom-u-thai ${ }^{\mathrm{b}, \mathrm{d}, *}$ \\ ${ }^{a}$ Plant Genetic Resources and Nutrition Laboratory, Chiang Mai University, Chiang Mai 50200 Thailand \\ b Agronomy Division, Department of Plant Science and Natural Resources, Faculty of Agriculture, \\ Chiang Mai University, Chiang Mai 50200 Thailand \\ c Highland Research and Training Centre, Faculty of Agriculture, Chiang Mai University, \\ Chiang Mai 50200 Thailand \\ d Lanna Rice Research Centre, Chiang Mai University, Chiang Mai 50200 Thailand
}

*Corresponding author, e-mail: chanakan15@hotmail.com, chanakan.p@cmu.ac.th

Received 19 Apr 2015

Accepted 8 Dec 2015

\begin{abstract}
Genotypic variation and nutritional quality of rice has been established, but environmental effects on the genotype are unknown. This study determines how nutritional quality, such as pericarp colour and antioxidant capacity, of purple rice can vary when grown under different environments. Nine purple rice genotypes and Khao Dok Mali 105 (KDML105, a non-pigmented rice) were grown at 2 different altitudes ( $330 \mathrm{~m}$ and $800 \mathrm{~m}$ above mean sea level, designated lowland and highland, respectively) at Chiang Mai, Thailand. Grain yield, Zn, anthocyanin concentration, and anti-oxidative capacity of the rice genotypes varied significantly in direction and magnitude. Grain Zn was higher in the lowland, but with differences between altitudes ranging from $16 \%$ to $50 \%$ among the purple rice genotypes, while non-pigmented KDML105 was among the lowest in grain Zn concentration at both altitudes. Some genotypes produce rice with more intense pigmentation and higher concentration of monomeric anthocyanin in the highland, some did so in the lowland, while no altitude effects were seen in others. Antioxidant capacity (Trolox equivalent) of the rice increased with increasing concentration of anthocyanin $\left(R^{2}=0.72, p<0.01\right)$, and varied in a multiple regression with anthocyanin and $\mathrm{Zn}$ concentration $\left(R^{2}=0.75, p<0.01\right)$. The effect of altitude on variation of grain nutritional quality among purple rice genotypes between the two growing conditions should be taken into consideration in efforts to enhance valuable nutrients in agronomic and breeding programmes.
\end{abstract}

KEYWORDS: pigmented rice, coloured rice, anthocyanin, iron, zinc, elevation

\section{INTRODUCTION}

Purple or black rice with pigmented pericarp is well established in Asia's traditional pharmacopoeias ${ }^{1,2}$. Traditional medicine in China uses pigmented rice to prevent anaemia and to improve blood circulation, kidney function, and eyesight ${ }^{3}$. Black rice porridge is given to aid recovery of invalids; one Chinese genotype is known as "healing of broken bones" ${ }^{4}$. Claims of medicinal properties of purple rice in Thailand, where it is known as "Khao Kam", include stopping bleeding after childbirth, reducing fever to curing skin disease and diarrhoea ${ }^{5}$. In Korea black rice is known as a health food ${ }^{6}$.

Pigmented layers of plant cells and tissues have been reported to contain suites of compounds with anti-oxidative properties which can protect against oxidative damages implicated in a range of diseases, including cancer and cardiovascular ailments ${ }^{7}$. The anti-oxidative activities have been found to be associated mainly with phenolic compounds ${ }^{8-11}$. In purple rice, the main phenolic has been identified as anthocyanin ${ }^{8}$, specifically cyanidin-3-glucoside and peonidin-3-glucoside ${ }^{12}$, malvidin, pelargonidin-3,5-diglucoside, cyanidin-3glucoside and cyanidin-3,5-diglucoside ${ }^{9}$; cyanidin3-glucoside, pelargonidin-3-glucoside ${ }^{10}$.

A wide variation of the antioxidant compounds has been reported among different Thai purple rice genotypes. Yodmanee et $\mathrm{al}^{13}$ reported the variation of anthocyanin, polyphenol and iron among 8 coloured rice genotypes (red and purple pericarp) varied from 9-245 mg cyanidin-3-glucoside/100 g DW, from 58-329 mg gallic acid equivalent/100 g DW, from $0.9-1.6 \mathrm{mg} / 100 \mathrm{~g} \mathrm{DW}$, respectively. Genotypic variation in the concentration of antioxidative compounds has thus been clearly established. Among the very few studies that examined 
Table 1 Local Thai purple rice genotypes used in the experiment and a non-pigmented KDML105.

\begin{tabular}{lrr}
\hline Variety (Symbol) & \multicolumn{2}{c}{ Original ecotype } \\
\cline { 2 - 3 } & Altitude & $\begin{array}{r}\text { Water } \\
\text { regime }\end{array}$ \\
\hline Hom Luem Pua (HLP) & Highland & $\begin{array}{r}\text { Upland } \\
\text { Kham Doi Saket (KDK) }\end{array}$ \\
Kham Nongbualumpu 1 (KNL1) & Lowland & Wetland \\
Kham Nongbualand \\
Kham Nongbualumpu 3 (KNL3) & Lowland & Wetland \\
Kham Nongbualumpu 4 (KNL4) & Lowland & Wetland \\
Kham Petchaboon 1 (KPB1) & Highland & Upland \\
Kham Petchaboon 2 (KPB1) & Highland & Upland \\
Bieisu (BES) & Highland & Upland \\
Khao Dok Mali 105 (KDML105) & Lowland & Wetland \\
\hline
\end{tabular}

$\dagger$ Described by the local condition from which the genotype originated: lowland, grown at elevation < $500 \mathrm{~m}$; highland, grown at elevation $>500 \mathrm{~m}$; upland, grown in aerobic soil; wetland, grown in waterlogged soil submerged under a few centimetres of water.

the effect of the environment, a possibility that biologically active property of purple rice genotypes may be influenced differently by environment was suggested by a field experiment of 7 back glutinous upland rice grown in different altitudes and a small pot study of two Thai purple rice varieties which were affected differently by altitudes and nitrogen fertilizer in their anthocyanin content ${ }^{14,15}$. However, the genotype by environmental interaction effects on characteristics and nutritional qualities such as pericarp colour and antioxidant capacity have as yet to be clearly established. This study evaluated the effect of altitude on grain yield, pericarp colour, zinc, and monomeric anthocyanin content and antioxidant capacity in 9 Thai purple rice genotypes.

\section{MATERIALS AND METHODS}

\section{Plant culture}

Nine purple rice genotypes (Table 1) and Khao Dok Mali 105 (KDML105), a non-pigmented rice used as standard check, were grown in the field in the wet season (June-November) of 2012. The experiment was carried out in 2 altitudes in Chiang Mai, northern Thailand designated lowland and highland (Chiang Mai University: $18.8026^{\circ} \mathrm{N}, 98.9516^{\circ} \mathrm{E}$, $330 \mathrm{~m}$ above msl, and Tung Luang village, Mae Win subdistrict, Mae Wang district: $18.6125^{\circ} \mathrm{N}$, $98.7750^{\circ} \mathrm{E}, 800 \mathrm{~m}$ above $\mathrm{msl}$ ). Soil fertility characteristics at the altitudes determined on 4 replicated samples to $30 \mathrm{~cm}$ depth were $\mathrm{pH}$ (1:1, soil:water), available phosphorus (Bray II), and DTPA extracted Zn. Rice plants at both altitudes were grown as upland rice, i.e., on aerobic soil. Briefly, the seed was soaked in water overnight and incubated moist until germinated and raised as seedlings for 30 days. Single seedlings were transplanted into hills at $25 \times 25 \mathrm{~cm}$ spacing in prepared field of each site. Nitrogen fertilizer was applied at the rate of $75 \mathrm{~kg} \mathrm{~N} / \mathrm{ha}$, half at maximum tillering and half at flowering at both sites. Rice seed was harvested at maturity. Grain yield was adjusted to $14 \%$ moisture content.

\section{Sample preparation}

The rice seed was de-husked to produce unpolished rice with a laboratory husker (Model P-1 from Ngek Seng Huat Co. Ltd., Thailand). The metal parts of de-husker were carefully cleaned to avoid zinc contamination between samples. Optical quality was measured with a chroma meter (model CR-300, Minolta, Osaka, Japan), with the $L^{*} a^{*} b^{*}$ values, with the $L^{*}$ value indicating brightness. The difference in optical quality between the 2 altitudes was calculated as in the following equation ${ }^{16}$ :

$$
\Delta E_{a b}^{*}=\sqrt{\left(\Delta L^{*}\right)^{2}+\left(\Delta a^{*}\right)^{2}+\left(\Delta b^{*}\right)^{2}}
$$

where $\Delta E_{a b}^{*}$ is the magnitude of difference of colour between 2 samples, $\Delta L^{*}, \Delta a^{*}$, and $\Delta b^{*}$ are the differences of $L^{*}, a^{*}$, and $b^{*}$ values between 2 altitudes, respectively. The high value of $\Delta E_{a b}^{*}$ indicated the extreme difference of the pigmented colour according to the equipment capacity.

\section{Chemical analysis}

Samples were oven dried at $75^{\circ} \mathrm{C}$ for $72 \mathrm{~h}$ before Zn was determined using a Hitachi Z-8230 atomic absorption spectrophotometer ${ }^{17}$. Monomeric anthocyanin was determined by the $\mathrm{pH}$-differential method $^{18,19}$. Briefly, $2.5 \mathrm{~g}$ freeze dried samples were extracted in double deionized water (DDI) water at $50^{\circ} \mathrm{C}$ for $30 \mathrm{~min}$. The extracted solution was filtered with filter paper before preparing two dilutions. Volume of one fraction was adjusted with $\mathrm{KCl}$ buffer, $\mathrm{pH}$ 1.0, and the other fraction with sodium acetate buffer, $\mathrm{pH}$ 4.5. Each dilution was allowed to equilibrate for $15 \mathrm{~min}$. Absorbance of the first dilution was measured at $520 \mathrm{~nm}$ and the second dilution at $700 \mathrm{~nm}$, against a blank cell filled with distilled water. Absorbance readings were made after $15 \mathrm{~min}$ and completed within $45 \mathrm{~min}$. The absorbance of the diluted sample $(A)$ was calculated as $A=\left(A_{520}-A_{700}\right)_{\mathrm{pH} 1.0}-\left(A_{520}-A_{700}\right)_{\mathrm{pH} 4.5}$. 
The monomeric anthocyanin pigment concentration $(\mathrm{mg} / \mathrm{l})$ in the original sample was calculated as $(A M f B) /(\varepsilon L)$, which was converted to mg of total anthocyanin content per $100 \mathrm{~g}$ sample; here $M=$ $449.2 \mathrm{~g} / \mathrm{mol}$ is the molecular weight of cyanidin-3glucoside, $f$ is the dilution factor, $B=1000 \mathrm{mg} / \mathrm{g}$ is a conversion factor, $\varepsilon=269001 \mathrm{~mol}^{-1} \mathrm{~cm}^{-1}$ is the molar absorptivity of the pigment, and $L=$ $1 \mathrm{~cm}$ is the path length. The trolox equivalent antioxidant capacity (TEAC) was performed using the DPPH Free Radical Scavenging Method ${ }^{20}$. The DPPH reagent $(0.395 \mathrm{~g})$ was dissolved in $1000 \mathrm{ml}$ of methanol for preparing the DPPH reagent solution. About $0.1 \mathrm{~g}$ of ground sample was extracted with methanol and filtered with $0.5 \mu \mathrm{m}$ nylon membrane before measuring for the DPPH free radical scavenging test. Then $0.5 \mathrm{ml}$ of DPPH solution and $1.6 \mathrm{ml}$ methanol were added into the sample solution and transferred to a spectrophotometer cuvette. The reaction solution was carried out in a dark room at $25^{\circ} \mathrm{C}$ for $20 \mathrm{~min}$. Then the absorbance of the reaction mixture was monitored at $517 \mathrm{~nm}$ using a UV-Vis spectrophotometer. Radical scavenging activity was calculated as $\left(A_{\mathrm{c}}-A_{\mathrm{s}}\right) / A_{\mathrm{c}}$, where $A_{\mathrm{s}}$ and $A_{\mathrm{c}}$ are the absorbances of the sample and control, respectively.

The DPPH scavenging activity percentage of the absorbance of DPPH was calculated by plotting against each quantity of the extraction to produce a regression line. Trolox $(0.4 \mathrm{mM})$ in methanol was used as a standard to convert the inhibition capability of the samples to the trolox equivalent antioxidant activity. The ratio of the slopes of the regression lines of the extract solution and the trolox solution was defined as the trolox equivalent antioxidant capacity. Then it was converted to $\mu \mathrm{mol}$ trolox equivalent/g rice.

The Fe reducing antioxidant power (FRAP) was performed according to the method described by Benzie and Strain ${ }^{21}$. Briefly, freshly prepared FRAP reagent consisted of $0.1 \mathrm{M}$ acetate buffer $(\mathrm{pH} 4.0)$, $0.5 \%(\mathrm{w} / \mathrm{v}) 1,10$ phenanthroline in $10 \%$ methanol, and $0.3 \mathrm{mM} \mathrm{FeCl}_{3}$ in a ratio of $1: 1: 1(\mathrm{v} / \mathrm{v} / \mathrm{v})$. The $2 \mathrm{ml}$ of rice extract was mixed with $0.5 \mathrm{ml}$ of the phenanthroline and FRAP reagent. After $20 \mathrm{~min}$ of incubation at $37^{\circ} \mathrm{C}$, absorption was measured at $510 \mathrm{~nm}$ using a spectrophotometer. Aqueous or methanolic solutions of known Fe(II) concentration were used for calibration in the FRAP assay. FRAP values, expressed as $\mu \mathrm{mol}$ of $\mathrm{Fe}(\mathrm{II})$ equivalent per $100 \mathrm{~g}$ rice, were obtained by comparing the absorption change in the test mixture with doses obtained from $\mathrm{Fe}(\mathrm{II})$ standard curve.

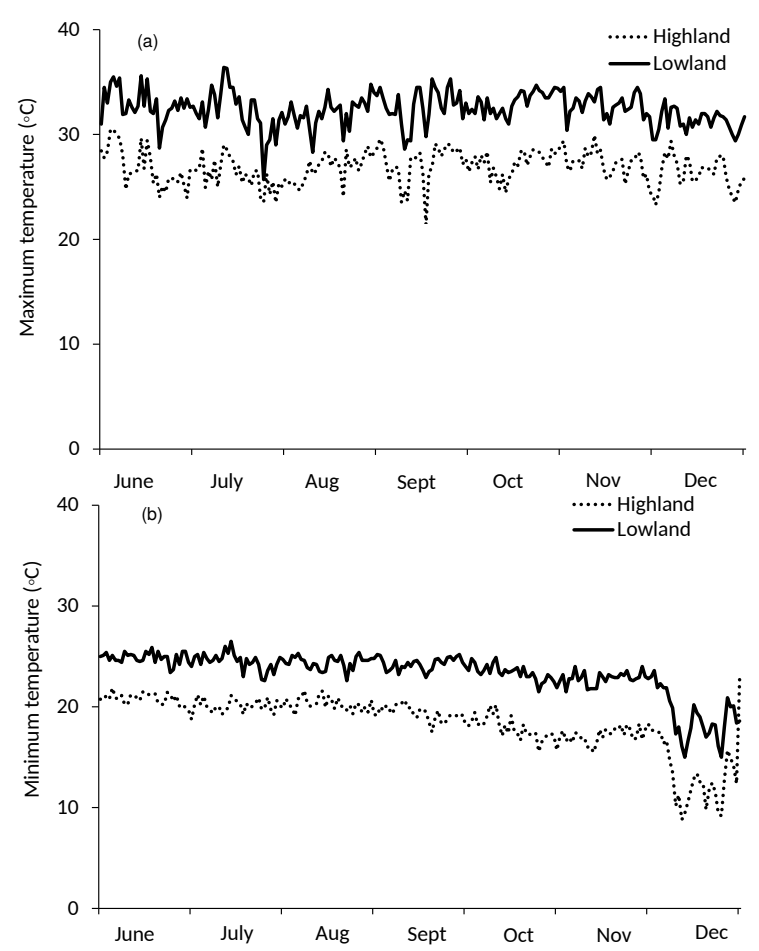

Fig. 1 Meteorological data during planting (June-Dec. 2012) at lowland and highland altitudes: (a) maximum temperature, (b) minimum temperature.

\section{Data analysis}

The data were subjected to combined ANOVA and the means that were significantly different were separated at $p<0.05$ by the least significant difference test. Certain sets of data were also subjected to correlation and regression analysis.

\section{RESULTS}

During the growing season the highland site was cooler $\left(18-27^{\circ} \mathrm{C}\right.$ for highland, compared with $23-$ $32^{\circ} \mathrm{C}$ for lowland) and more humid (69-100\% for highland and $55-91 \%$ for lowland) than the lowland site with similar average rain fall at both altitudes (Fig. 1). More than half of the genotypes grown at the highland reached flowering before lowland site, except in KNL1, KPB2, and BES which had the reverse result, while KDK and KDML105 had similar flowering date in the two altitudes (Table 2). However, when counted the day from seeds planting until flowering, almost all genotypes grown at lowland had fewer days than highland site with the difference of day ranged from 1-36 days between the 2 altitudes (Table 2). All genotypes at both altitudes matured after 43 days after flowering, except the genotype KNL1 which took 35 days from flowering 


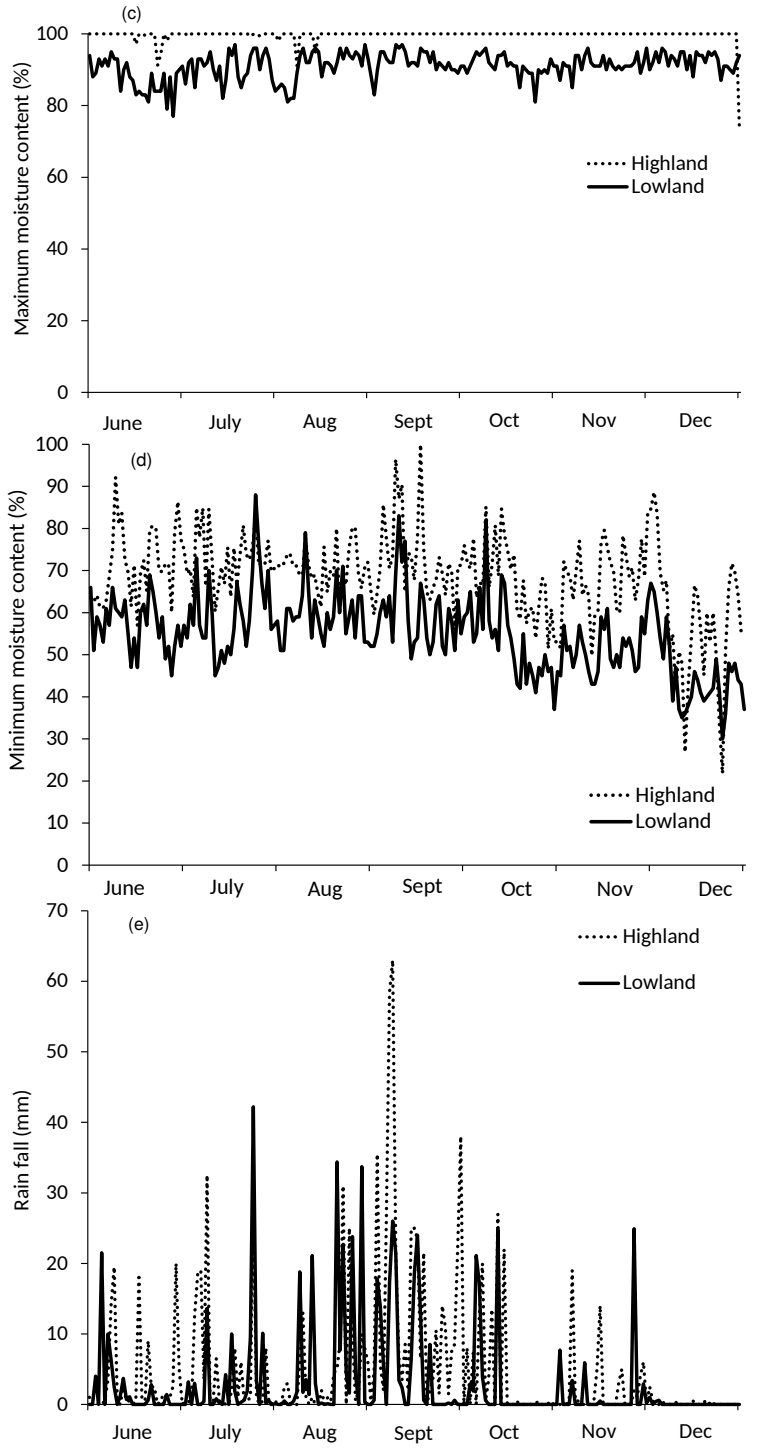

Fig. 1 (Cont.) Meteorological data during planting (June-Dec. 2012) at lowland and highland altitudes: (c) maximum moisture content, (d) minimum moisture content, (e) rain fall.

to maturity in the lowland but only 30 days in the highland (Table 2).

The soil was acidic sandy loam at both sites, with soil $\mathrm{pH}$ of 4.1 and $0.4 \mathrm{mg}$ DTPA extractable $\mathrm{Zn} / \mathrm{kg}$ at the highland altitude and soil $\mathrm{pH}$ of 5.5 and $1.5 \mathrm{mg}$ DTPA extractable $\mathrm{Zn} / \mathrm{kg}$ at the lowland altitude (Table 3).

\section{Altitude effects}

Altitude had different effects on grain yield of different genotypes ( $p<0.05$ ) (Fig. 2). The genotypes with higher grain yield at the highland than lowland
Table 2 Flowering date, days from planting to flowering, and days from flowering to maturity of 10 rice genotypes at 2 different locations.

\begin{tabular}{|c|c|c|c|c|c|c|}
\hline \multirow[t]{2}{*}{ Genotype } & \multicolumn{2}{|c|}{ Flowering date ${ }^{\dagger}$} & \multicolumn{2}{|c|}{$\mathrm{DPF}$} & \multicolumn{2}{|c|}{ DFM } \\
\hline & $\mathrm{L}$ & $\mathrm{H}$ & $\mathrm{L}$ & $\mathrm{H}$ & $\mathrm{L}$ & $\mathrm{H}$ \\
\hline LP & $26 / 09$ & $19 /$ & 82 & 90 & 43 & 42 \\
\hline KDK & $22 / 10$ & $22 / 10$ & 108 & 123 & 40 & 46 \\
\hline KNL1 & $17 / 10$ & $25 / 10$ & 103 & 126 & 35 & 30 \\
\hline NL2 & $24 / 09$ & $10 / 09$ & 80 & 81 & 45 & 47 \\
\hline KNL3 & $26 / 09$ & $12 / 09$ & 82 & 83 & 43 & 45 \\
\hline KNL4 & $26 / 09$ & $15 / 09$ & 82 & 86 & 43 & 42 \\
\hline KPB1 & $26 / 09$ & $10 / 09$ & 82 & 81 & 43 & 47 \\
\hline KРB2 & $26 / 09$ & $27 / 10$ & 82 & 118 & 43 & 43 \\
\hline BES & $26 / 09$ & $27 / 10$ & 82 & 118 & 43 & 38 \\
\hline KDML105 & $26 / 10$ & $27 / 10$ & 92 & 118 & 43 & 41 \\
\hline
\end{tabular}

$\dagger$ Date of 2012.

DPF: days from planting to flowering; DFM: days from flowering to maturity; L: lowland; H: highland.

Table 3 Soil fertility characteristics at 2 experimental altitudes (lowland and highland).

\begin{tabular}{lcc}
\hline Soil fertility characteristics $^{\dagger}$ & Lowland & Highland \\
\hline Texture & Sandy loam & Sandy loam \\
pH (1: 1 , Soil : Water) & 5.5 & 4.1 \\
P (mg/kg) (Bray II) & 59.0 & 52.1 \\
Zn (mg/kg) (DPTA extraction) & 1.5 & 0.4 \\
\hline
\end{tabular}

$\dagger$ Values are means of 4 replications.

altitude were HLP, KNL2, KNL3, KPB1, and KPB2, the reverse was found with KDK, KNL1 and the lowland variety KDML105, while altitude had no effect on the yield in KNL4 and BES. Effects of altitude on grain pigmentation differed among the rice genotypes in both magnitudes and direction (Table 4). The 2 genotypes with the largest effect of altitude on pigmentation intensity, KNL1 and KNL3, differed in the altitude at which the pigmentation was more intense. The lower brightness measure of $L$ value which indicated more intense pigmentation was found in the highland in KNL1 but in the lowland in KNL3. Incidentally, there was a significant altitude effect on the optical quality of the non-pigmented KDML105 which showed a slightly brighter hue in the lowland than in the highland. There was a strong interaction between the effect of genotype and environment $(p<0.01)$ on grain Zn concentration, monomeric anthocyanin concentration, and anti-oxidative capacities determined by DPPH and FRAP methods in rice of the 10 genotypes ( 9 Thai purple rice genotypes and non- 


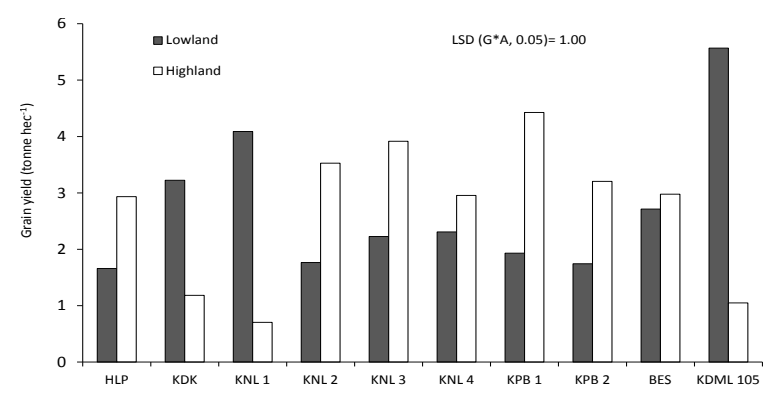

Fig. 2 Grain yield (14\% moisture content) of 9 Thai purple rice genotypes and non-pigmented KDML105 grown at 2 altitudes (lowland and highland).

Table 4 Variation in pigmentation intensity between locations $\left(\Delta E_{a b}^{*}\right)$ and $L^{*}$ value for brightness.

\begin{tabular}{llcr}
\hline Genotype & \multicolumn{2}{c}{$L^{*}$ value $^{\dagger}$} & \multicolumn{1}{c}{$\Delta E_{a b}^{*}$} \\
\cline { 2 - 3 } & $\begin{array}{c}\text { lowland } \\
(300 \mathrm{~m})\end{array}$ & $\begin{array}{c}\text { highland } \\
(800 \mathrm{~m})\end{array}$ \\
\hline HLP & 24.52 & 23.06 & $3.7 \pm 0.3^{\ddagger}$ \\
KDK & 21.59 & 21.41 & $3.0 \pm 0.6$ \\
KNL1 & $23.92^{\mathrm{a}}$ & $38.45^{\mathrm{b}}$ & $17.5 \pm 0.7$ \\
KNL2 & 24.61 & 23.92 & $3.0 \pm 0.3$ \\
KNL3 & $31.08^{\mathrm{b}}$ & $22.85^{\mathrm{a}}$ & $15.5 \pm 2.0$ \\
KNL4 & 23.28 & 24.23 & $3.8 \pm 0.4$ \\
KPB1 & $26.52^{\mathrm{b}}$ & $22.36^{\mathrm{a}}$ & $4.8 \pm 1.2$ \\
KPB2 & 23.88 & 22.46 & $4.0 \pm 2.4$ \\
BES & 24.50 & 26.56 & $5.8 \pm 2.0$ \\
KDML105 & 62.66 & 59.69 & $5.2 \pm 1.0$ \\
\hline
\end{tabular}

$\dagger$ For the same variety, the means marked with different letters were significantly different between 2 altitudes $(p<0.05)$.

$\$$ Values are mean \pm standard error of mean with 3 replications.

pigmented KDML105) grown at 2 different altitudes (Table 5). Grain Zn concentration was affected by both genotype and altitude $(p<0.01)$ (Fig. 3). Purple rice grown in the lowland had higher $\mathrm{Zn}$ concentration than that grown at the highland, but with the difference between altitudes ranging from 16$50 \%$ among the genotypes. For the non-pigmented KDML105, which was among the lowest in grain $\mathrm{Zn}$, there was no altitude effect on its grain $\mathrm{Zn}$ concentration. The highest grain $\mathrm{Zn}$ concentration (33-35 $\mathrm{mg} \mathrm{Zn/kg}$ ) was found in the genotypes HLP, KNL2 and KNL3 grown in the lowland, but in the highland the grain $\mathrm{Zn}$ in these genotypes was one third lower.

Monomeric anthocyanin concentration of the purple rice genotypes varied with the altitude where they were grown $(p<0.01)$ (Fig. 4$)$. The genotypes
Table 5 Mean square of the combined ANOVA for grain Zn concentration.

\begin{tabular}{|c|c|c|c|c|c|}
\hline \multirow[t]{2}{*}{$\overline{\text { Source }^{\dagger}}$} & \multirow[t]{2}{*}{$\mathrm{df}$} & \multirow{2}{*}{$\begin{array}{c}\mathrm{Zn} \\
(\mathrm{mg} / \mathrm{kg})\end{array}$} & \multirow{2}{*}{$\begin{array}{c}\text { Monomeric } \\
\text { anthocyanin } \\
(\mathrm{mg} / 100 \mathrm{~g})\end{array}$} & \multicolumn{2}{|c|}{ Anti-oxidative capacity } \\
\hline & & & & $\begin{array}{c}\text { DPPH } \\
(\mathrm{g} / 100 \mathrm{~g})\end{array}$ & $\begin{array}{c}\text { FRAP } \\
(\mathrm{mol} / 100 \mathrm{~g})\end{array}$ \\
\hline$G \times A$ & $\begin{array}{l}9 \\
1 \\
9\end{array}$ & $\begin{array}{r}50.36^{* * *} \\
758.99^{* * *} \\
24.32^{* * *}\end{array}$ & $\begin{array}{r}1920.8^{* * *} \\
8.8^{\mathrm{NS}} \\
150.0^{* * *}\end{array}$ & & \\
\hline $\begin{array}{l}\text { olec } \\
\text { ror }\end{array}$ & 36 & 1.22 & 18.3 & 0.62 & 0.060 \\
\hline
\end{tabular}

${ }^{\dagger} G$ : genotype; $A$ : altitude.

"Significance $p<0.01,{ }^{\text {NS }}$ Not significant.

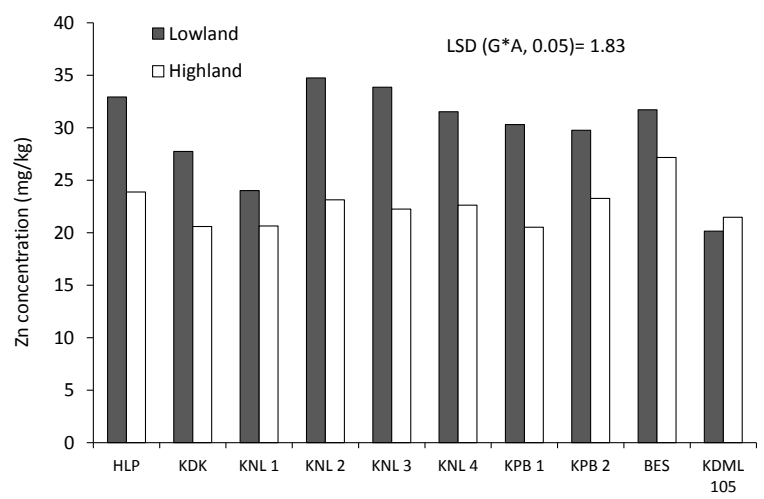

Fig. 3 Zinc concentrations in unpolished rice of 9 Thai purple rice genotypes and non-pigmented KDML105 grown at 2 altitudes (lowland and highland).

with the higher anthocyanin concentration in the lowland were HLP and KDK, while those with higher anthocyanin in the highland were KNL3, KNL4, $\mathrm{KPB} 1$, and BES. The remaining genotypes and nonpigmented KDML105 with negligible anthocyanin, showed no effect of altitude on their anthocyanin concentration. The antioxidant capacity determined by DPPH and FRAP methods, that were only weakly correlated $\left(R^{2}=0.13, p<0.05\right)$, showed different variation by genotype and altitude. The antioxidant capacity determined as TEAC by the DPPH method was high in all purple rice genotypes compared with the non-pigmented KDML105, but the capacity varied with genotype and altitude (Fig. 5). The TEAC of rice grain grown at the highland was about 4 times higher than at the lowland in KNL1 and KDML105, while the other genotypes showed much milder altitude effect. FRAP was also affected by the genotype and altitude (Fig. 6). The effect of altitude on FRAP was more marked, with the activity in the genotypes HLP, KDK, KNL1, KNL2, BES, and KDML105 grown in the lowland $2-4$ folds higher than when grown in the highland, while the geno- 


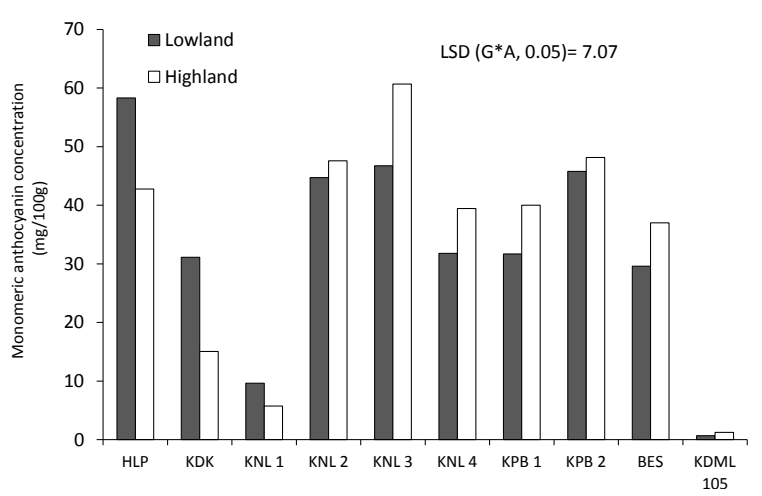

Fig. 4 Monomeric anthocyanin concentrations in unpolished rice of 9 Thai purple rice genotypes and nonpigmented KDML105 grown at 2 altitudes (lowland and highland).

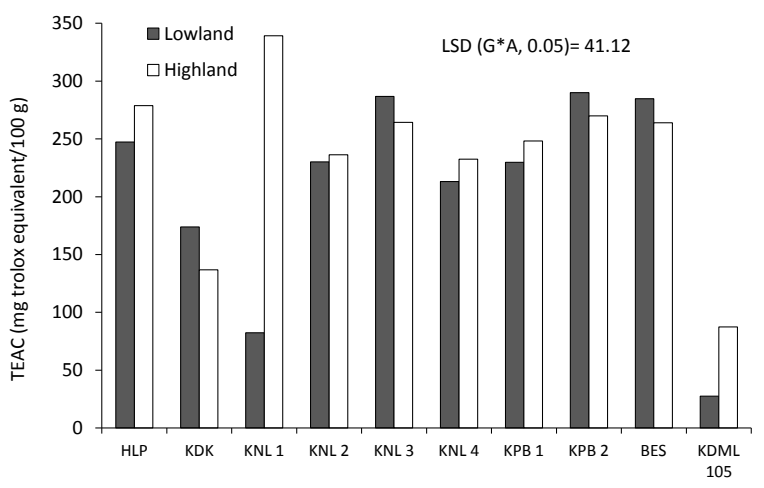

Fig. 5 Trolox equivalent antioxidant capacities (TEAC) in unpolished rice of 9 Thai purple rice genotypes and nonpigmented KDML105 grown at 2 altitudes (lowland and highland).

types KNL4 and KPB1 grown in the highland had 3-7 folds of their FRAP value in lowland, with no altitude effect in the remaining genotypes.

\section{Relationship between quality characteristics and between yield and quality}

There was a close association between anthocyanin content and TEAC of the rice genotypes when grown at the lowland altitude $\left(R^{2}=0.73, p<0.05\right)$, but not when the rice genotypes were grown at the highland altitude (Fig. 7), while the association was much weaker between FRAP and the anthocyanin $\left(R^{2}=0.17, p<0.05\right)$. The TEAC also varied with $\mathrm{Zn}$ and anthocyanin concentration in a multiple regression $\left(R^{2}=0.75, p<0.05\right)$,

$$
\mathrm{DPPH}=31.399+2.656[\mathrm{Zn}]+3.133[\text { Antho }],
$$

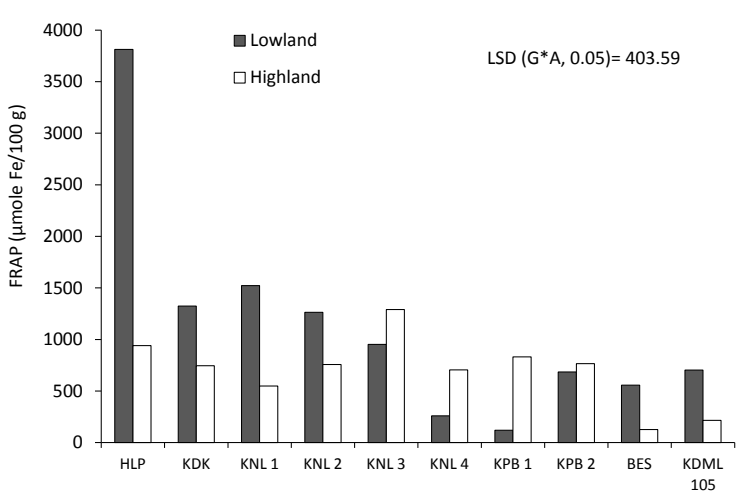

Fig. 6 Ferric reducing antioxidant power (FRAP) of unpolished rice 9 Thai purple rice genotypes and nonpigmented KDML105 grown at 2 altitudes (lowland and highland).

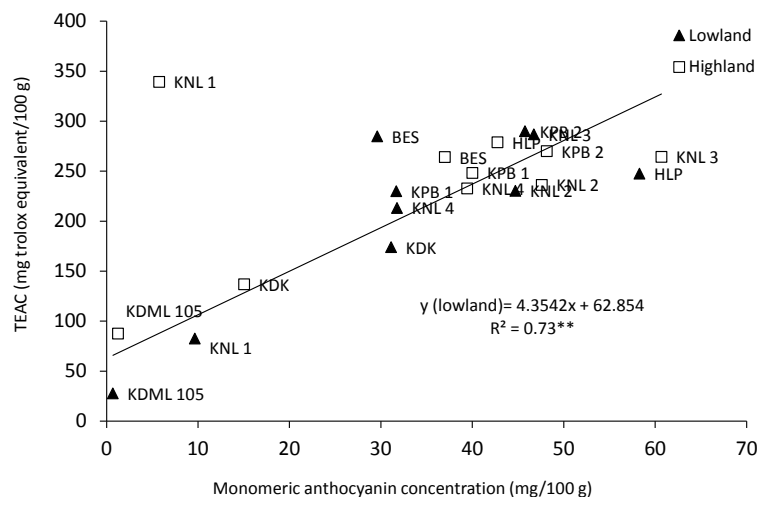

Fig. 7 Relationship between monomeric anthocyanin concentration and trolox equivalent antioxidant capacity (TEAC) of 9 Thai purple rice genotypes and nonpigmented KDML105 grown at 2 altitudes (lowland and highland) $(n=10)$.

and so did FRAP but with much weaker association $\left(R^{2}=0.15, p<0.05\right)$,

FRAP $=-163.798+22.164[\mathrm{Zn}]+14.700$ [Antho $].$

The association between grain $\mathrm{Zn}$, anthocyanin and antioxidant capacity and grain yield varied significantly between the two altitudes (Fig. 8). The concentration of grain $\mathrm{Zn}$ in the highland did not vary with grain yield, but in the lowland grain $\mathrm{Zn}$ concentration declined when grain yield increased $\left(R^{2}=0.84, p<0.05\right)$ (Fig. 8a). On the other hand, altitude had different effects on the relationship between grain yield and anthocyanin concentration (Fig. 8b). With increasing grain yield the concentration of anthocyanin increased at the highland altitude $\left(R^{2}=0.82, p<0.05\right)$ but declined at the 

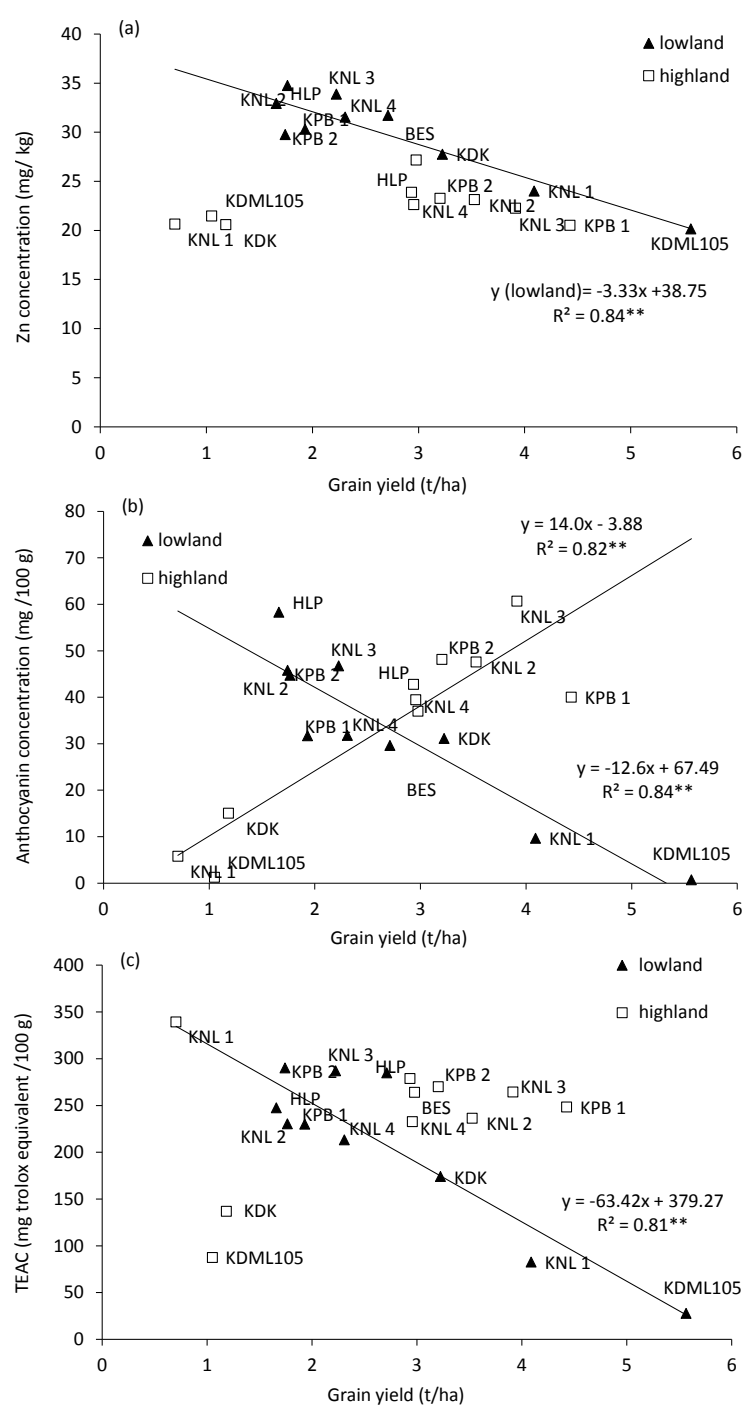

Fig. 8 The relationship between grain yield (14\% moisture content) and (a) grain $\mathrm{Zn}$ concentration, (b) anthocyanin concentration, and (c) antioxidant capacity, of 9 Thai purple rice genotypes and non-pigmented KDML105 grown at 2 altitudes (lowland and highland) $(n=10)$.

lowland altitude $\left(R^{2}=0.84, p<0.05\right)$. No correlation was observed between TEAC and grain yield in the highland, but in the lowland the correlation was negative $\left(R^{2}=0.81, p<0.05\right.$, Fig. $\left.8 c\right)$.

\section{DISCUSSION}

This study established that there may be a strong interaction between genotype and altitude in their effects on the nutritional quality characteristics and grain yield of the purple rice. There was also different association between the quality characteristics and yield and quality in the highland and lowland. A previous investigation reported that tannin concentration, phenolic content and antioxidant efficiency among 133 coloured rice genotypes tested were independent of seasonal changes when grown in different years at the same altitude ${ }^{22}$. In contrast, the variation in altitude effect on the monomeric anthocyanin (a water soluble form of anthocyanin and considered as the primary bioactive compound in purple rice ${ }^{3,23,24}$ ) of different purple rice genotypes found here suggested a much larger environmental effect than the previous study. It remains to be elucidated whether the effect is the result of differences in the soil or micro-climate due to $500 \mathrm{~m}$ difference in elevation.

The effects of genotype and soil condition on variation in grain $\mathrm{Zn}$ concentration and anthocyanin, but not on pigmentation or antioxidant capacity of rice have been previously reported ${ }^{15,25,26}$. Genotype by environment interaction contributed to the total variation in grain anthocyanin content of 7 black glutinous upland rice varieties grown at different altitudes ${ }^{15}$. In pear, low temperature was found to induce red coloration, while anthocyanin levels increased with increasing irradiance level with genotype dependent ${ }^{27}$. It has also been reported that antioxidant capacity of strawberry varied among different genotypes and growing condition ${ }^{28}$. Stability of traits over different locations is desirable and an important issue in breeding programmes, especially when highly promising genotypes for the traits is identified. However, stability associated with low performing genotypes, as found here, is of little value.

Anthocyanin has been well established as a major inhibitor of malignant growth in human cells ${ }^{29}$ and demonstrated excellent anti-inflammatory and antioxidant property ${ }^{30,31}$. The significant correlation between the TEAC and anthocyanin concentration both at the highland $\left(R^{2}=0.73, p<0.05\right)$ and lowland $\left(R^{2}=0.72, p<0.05\right)$ altitudes in this study is in agreement with these previous reports regarding the role of anthocyanin in antioxidant capacity of purple rice grain. The significant variation of the TEAC (1) and FRAP (2) in a multiple regression with anthocyanin in combination with $\mathrm{Zn}$ suggested an active role of $\mathrm{Zn}$ in antioxidant capacity. The additional effect of $\mathrm{Zn}$ on the antioxidant capacity in purple rice could be associated with its role in scavenging enzymes such as superoxide dismutase (SOD) in the form of CuZn-SOD. The enzyme, located in the mitochondria ${ }^{32}$ and glyoxysomes ${ }^{33}$, acts as a free-radical scavenging enzyme in plant $\mathrm{cell}^{34}$, detoxifies superoxide radicals occurring from 
photosynthetic activities and physiological stress responses, so mitigating their adverse effects on enzyme activity, integrity of polysaccharides, cell membrane and DNA and prevent cell death ${ }^{35}$. The role of $\mathrm{Zn}$ in antioxidant capacity of purple rice needs to be further investigated.

The antioxidant capacity determined with TEAC and FRAP agreed in that both reflected the interaction effects of genotype by altitude. The weak correlation between results from the two methods is in accordance with a previous report ${ }^{36}$, which discussed that antioxidant activity values determined by the FRAP method were not distinctive as those found by TEAC. The TEAC method is now more commonly used for evaluating antioxidant activity of plant material due to the simplicity of the assay and the fact that it can be used in aqueous and lipid phases ${ }^{37}$.

The negative correlation between grain yield and $\mathrm{Zn}$ concentration in the lowland altitude could be explained by the dilution of $\mathrm{Zn}$ in the tissue which might be related to the lower $\mathrm{Zn}$ concentration in the soil compared with those in the highland altitude which has higher $\mathrm{Zn}$ concentration in the soil and the concentration of grain Zn did not vary with grain yield. Similar findings on variation of grain $\mathrm{Zn}$ concentration when grown in different $\mathrm{Zn}$ concentration in the soil have been reported ${ }^{25,38}$. The reason for such increases in the anthocyanin by increasing of grain yield in the highland altitude is unknown. It might be related to the physiological function on enhancing grain yield as previously reported that increasing of phenolic and antioxidant activity also increased grain yield of black sorghum hybrids ${ }^{39}$. On the other hand, a negative correlation between grain yield and the anthocyanin was found in the lowland. Such different association between grain quality and yield between the 2 altitudes might be explained by the physiological responses of rice grown at different elevation such as average day/night temperature, photoperiod, and irradiance level which would require further studies to bring better understanding. Further research should also pay attention to physiological responses among rice genotypes from different original onfarm ecotype of altitude (highland and lowland) and water regime (wetland and upland varieties). This experiment was carried out by growing all the genotypes at both altitudes in the same aerobic condition, which is the predominant mode of rice production in the highlands. How the grain quality characteristics of different genotypes are affected by water regimes of their growing condition, i.e., aerobic versus waterlogged soil, is another avenue of exploration that should bring benefits to rice producers and consumers.

This study has established how nutritional quality, particularly anthocyanin content and the antioxidative capacity, as well as the intensity of pigmentation of purple rice genotypes may vary with the environment in which they are grown. Stability of these nutritional characteristics and environmental effects need to be considered when dealing with special quality of purple rice, while the controlling factors remain to be described.

Acknowledgements: This study received financial support from the Thailand Research Fund (RSA5580056) and Office of the Higher Education Commission under National Research University project.

\section{REFERENCES}

1. Ahuja U, Ahuja SC, Chaudhary N, Thakrar R (2007) Red rices - past, present and future. Asian Agri Hist 11, 291-304.

2. Appa Rao S, Schiller JM, Bounphanousay C, Inthapanya P, Jackson MT (2006) The colored pericarp (black) rice of Laos. In: Schiller JM, Chanphengxay MB, Linquist B, Appa Rao S (eds) Rice in Laos, International Rice Research Institute, Los Baños, Philippines, pp 175-86.

3. Deng GF, Xu XR, Zhang Y, Li D, Gan RY, Li HB (2013) Phenolic compounds and bioactivities of pigmented rice. Crit Rev Food Sci Nutr 53, 296-306.

4. Chaudhary R (2003) Speciality rices of the world: effect of WTO and IPR on its production trend and marketing. J Food Agr Environ 1, 34-41.

5. Kaladee D (2011) Khao Kam (Niaw Dam), The Neglected Thai Rice Resources, Chiang Mai Univ, Thailand, pp 1-161, [in Thai].

6. Park YS, Kim SJ, Chang HI (2008) Isolation of anthocyanin from black rice (Heugjinjubyeo) and screening of its antioxidant activities. Kor J Microbiol Biotechnol 36, 55-60.

7. Kehrer JP (1993) Free radicals as mediators of tissue injury and disease. Crit Rev Toxicol 23, 21-48.

8. Iqbal S, Bhanger MI, Anwar F (2005) Antioxidant properties and components of some commercially available varieties of rice bran in Pakistan. Food Chem 93, 265-72.

9. Zhang MW, Guo BJ, Zhang RF, Chi JW, Wei ZC, Xu ZH, Zhang Y, Tang XJ (2006) Separation, purification and identification of antioxidant compositions in blackrice. Agr Sci China 5, 431-40.

10. Yawadio R, Tanimori S, Morita N (2007) Identification of phenolic compounds isolated from pigmented rices and their aldose reductase inhibitory activities. Food Chem 101, 1616-25. 
11. Tabart J, Kevers C, Pincemail J, Defraigne J, Dommes $\mathrm{J}$ (2009) Comparative antioxidant capacities of phenolic compounds measured by various tests. Food Chem 113, 1226-33.

12. Hu C, Zawistowski J, Ling W, Kitts DD (2003) Black rice (Oryza sativa L. indica) pigmented fraction suppresses both reactive oxygen species and nitric oxide in chemical and biological model systems. J Agr Food Chem 51, 5271-7.

13. Yodmanee S, Karrila T, Pakdeechanuan P (2011) Physical, chemical and antioxidant properties of pigmented rice grown in Southern Thailand. Int Food Res $J$ 18, 901-6.

14. Kathuai W, Rerkasem B, Jamjod S, Phattarakul N, Prom-u-thai C (2013) Effects of nitrogen and water managements on yield and anthocyanin content in two purple glutinous rice varieties. Khon Kaen Agr J 41, 403-10, [in Thai].

15. Somsana P, Wattana P, Suriharn B, Sanitchon J (2013) Stability and genotype by environment interactions for grain anthocyanin content of Thai black glutinous upland rice (Oryza sativa). Sabrao J Breed Genet 45, 523-32.

16. Minolta (1991) Chroma meter CR-300/CR-310/CR321/CR-331/CR-331C instruction manual, Minolta Co. Ltd, Japan. pp 1-5.

17. Zarcinas BA, Cartwright B, Spouncer LR (1987) Nitric acid digestion and multi-element analysis of plant material by inductively coupled plasma spectrometry. Comm Soil Sci Plant Anal 18, 131-46.

18. Escribano-Bailón MT, Santos-Buelga C, Rivas-Gonzalo JC (2004) Anthocyanins in cereals. J Chrom A 1054, 129-41.

19. Wrolstad RE, Acree TE, An H, Decker EA, Penner MH, Reid DS, Schwartz SJ, Shoemaker CF, Sporns P (2001) Current Protocols in Food Analytical Chemistry, Wiley, New York.

20. Yue X, Xu Z (2008) Changes of anthocyanins, anthocyanidins, and antioxidant activity in bilberry extract during dry heating. $J$ Food Sci 73, 494-9.

21. Benzie IFF, Strain JJ (1999) Ferric reducing/antioxidant power assay: Direct measure of total antioxidant of biological fluids and modified version for simultaneous measurement of total antioxidant power and ascorbic acid concentration. Meth Enzymol 229, 15-27.

22. Goffman FD, Bergman CJ (2004) Rice kernel phenolic content and its relationship with antiradical efficiency. $J$ Sci Food Agr 84, 1235-40.

23. Hiemori M, Koh E, Mitchell AE (2009) Influence of cooking on anthocyanins in black rice (Oryza sativa L. japonica var. SBR). J Agr Food Chem 57, 1908-14.

24. Lee J, Durst RW, Wrolstad RE (2005) Determination of total monomeric anthocyanin pigment content of fruit juices, beverages, natural colorants, and wines by the $\mathrm{pH}$ differential method: collaborative study. J AOAC Int 88, 1269-78.
25. Graham R, Senadhira D, Beebe S, Iglesias C, Monasterio I (1999) Breeding for micronutrient density in edible portions of staple food crops: conventional approaches. Field Crop Res 60, 57-80.

26. Wissuwa M, Ismail A, Graham R (2008) Rice grain zinc concentrations as affected by genotype, native soil-zinc availability, and zinc fertilization. Plant Soil 306, 37-48.

27. Sun W, Qian M, Wu R, Niu Q, Teng Y, Zhang D (2014) Postharvest pigmentation in red Chinese sand pears (Pyrus pyrifolia Nakai) in response to optimum light and temperature. Postharvest Biol Tech 91, 64-71.

28. Gunduz K, Ozdemir E (2014) The effects of genotype and growing conditions on antioxidant capacity, phenolic compounds, organic and individual sugars of strawberry. Food Chem 155, 298-303.

29. Kamei H, Kojima S, Hasegawa M, Koide T, Umeda T, Yukawa T, Terabe K (1995) Suppression of tumor cell growth by anthocyanins in vitro. Canc Investig 13, 590-4.

30. Wang H, Nair MG, Strasburg GM, Chang YC, Booren AM, Gray JI, DeWitt DL (1999) Antioxidant and antiinflammatory activities of anthocyanins and their aglycone, cyanidin, from tart cherries. J Nat Prod 62, 294-6.

31. Liu M, Li XQ, Weber C, Lee CY, Brown J, Liu RH (2002) Antioxidant and antiproliferative activities of raspberries. J Agr Food Chem 50, 2926-30.

32. Duke MV, Salin ML (1985) Purification and characterization of an iron containing superoxide dismutase from a eucaryote, Ginkgo biloba. Arch Biochem Biophys 243, 305-14.

33. Sandalio LM, Del Río LA (1987) Localization of superoxide dismutas in glyoxysomes from Citrullus vulgaris. Functional implications in cellular metabolism. J Plant Physiol 127, 395-409.

34. Elstner EF (1982) Oxygen activation and oxygen toxicity. Annu Rev Plant Physiol 33, 73-96.

35. Fridovich I (1983) Superoxide radical: an endogenous toxicant. Annu Rev Pharmacol Toxicol 23, 239-57.

36. Jiapong S, Jiamyangyuen S (2012) Total anthocyanin content and antioxidant activity of germinated colored rice. Int Food Res $J$ 19, 215-21.

37. Sompong R, Siebenhandl-Ehn S, Linsberger-Martin G, Berghofer E (2011) Physicochemical and antioxidative properties of red and black rice varieties from Thailand, China and Sri Lanka. Food Chem 124, 132-40.

38. Phattarakul N, Rerkasem B, Li LJ, Wu LH, Zou CQ, Ram H, Sohu VS, Kang BS, et al (2012) Biofortification of rice grain with zinc through zinc fertilization in different countries. Plant Soil 361, 131-41.

39. Dykes L, Rooney WL, Rooney LW (2013) Evaluation of phenolics and antioxidant activity of black sorghum hybrids. J Cereal Sci 58, 278-83. 